\title{
Measurable residual disease-based strategy and reduced-intensity hematopoietic stem cell transplantation for acute myelogenous leukemia in children
}

\author{
Akihisa Sawada ${ }^{1}$, Sadao Tokimasa ${ }^{1}$, Masahiro Yasui ${ }^{1}$, Maho Sato ${ }^{1}$, Kohei Higuchi ${ }^{1}$, Mariko \\ Shimizu $^{1}$, Osamu Kondo ${ }^{1}$, Keisei Kawa ${ }^{1}$, and Masami Inoue ${ }^{1}$ \\ ${ }^{1}$ Osaka Women's and Children's Hospital
}

May 31, 2021

\begin{abstract}
Background. Measurable residual disease (MRD) is a powerful prognostic factor in patients with acute myelogenous leukemia (AML). We previously conducted a prospective study on an MRD-based strategy for the treatment of children with AML, and its significance has been reported. The present retrospective study is a pooled analysis of 34 patients who were registered after the completion of the previous study. Procedure. Reduced-intensity conditioning (RIC) followed by allogeneic hematopoietic stem cell transplantation (RIC-HSCT) was adopted to increase survival rates and minimize toxicities. The strategy was also refined with a minor modification, with WT1 expression levels in peripheral blood, as an MRD marker after a 2nd course of chemotherapy (consolidation course 1), being measured in addition to WT1, chimeric mRNA, and aberrant surface markers in bone marrow. Results. Five-year relapse-free and overall survival rates were 76.5 and $85.2 \%$, respectively. RIC-HSCT was safely and effectively performed on MRD-positive patients. Among patients who underwent RIC-HSCT, re-emerging/rising MRD and high levels of MRD before HSCT were risk factors for disease relapse early after HSCT. Conclusions. The MRD-based strategy and RIC-HSCT worked well for children with AML. HLA-haploidentical peripheral blood transplantation following RIC may be a promising candidate for further study on patients at very high risk of relapse.
\end{abstract}

\section{Hosted file}

AML+MRD_text_210528.doc available at https://authorea.com/users/417108/articles/524330measurable-residual-disease-based-strategy-and-reduced-intensity-hematopoietic-stemcell-transplantation-for-acute-myelogenous-leukemia-in-children

\section{Hosted file}

AML+MRD_Tab1_inDoc_210510.doc available at https://authorea.com/users/417108/articles/524330measurable-residual-disease-based-strategy-and-reduced-intensity-hematopoietic-stemcell-transplantation-for-acute-myelogenous-leukemia-in-children

\section{Hosted file}

AML+MRD_Tab2_inDoc_210510.doc available at https://authorea.com/users/417108/articles/524330measurable-residual-disease-based-strategy-and-reduced-intensity-hematopoietic-stemcell-transplantation-for-acute-myelogenous-leukemia-in-children 


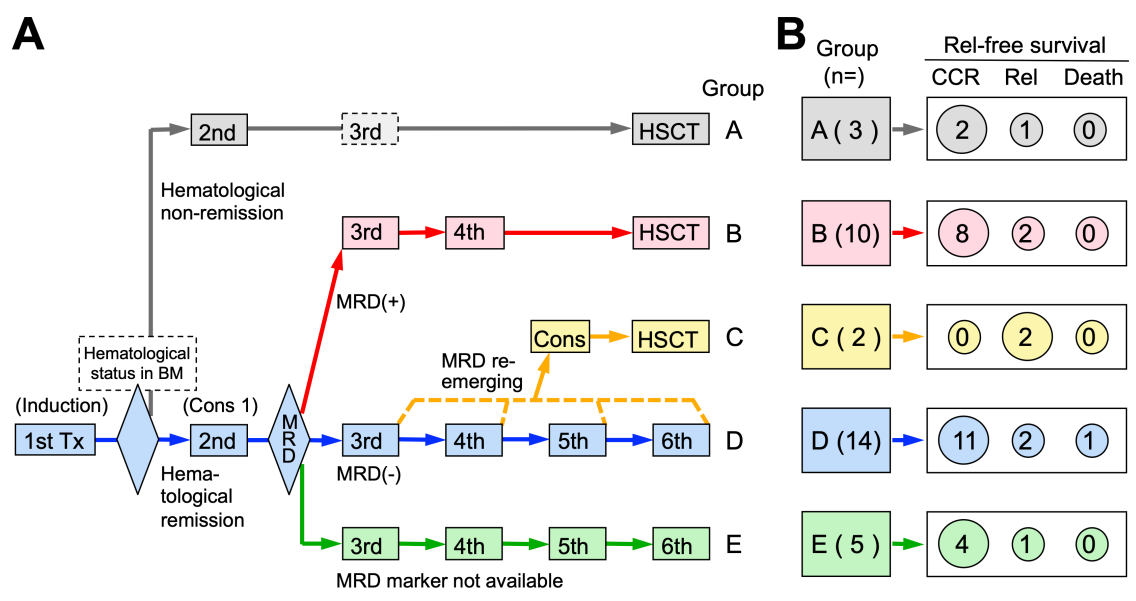

Figure 1
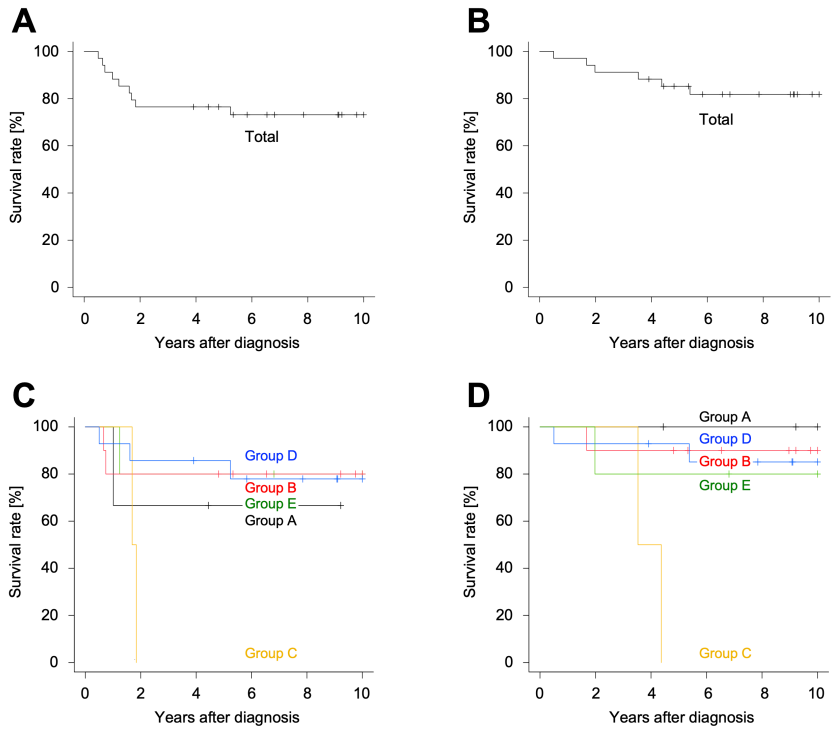

Figure 2 